\title{
The relation of low glycaemic index fruit consumption to glycaemic control and risk factors for coronary heart disease in type 2 diabetes
}

\author{
D. J. A. Jenkins • K. Srichaikul • C. W. C. Kendall • J. L. Sievenpiper • S. Abdulnour • \\ A. Mirrahimi • C. Meneses • S. Nishi • X. He • S. Lee • Y. T. So • A. Esfahani • \\ S. Mitchell • T. L. Parker $\cdot$ E. Vidgen $•$ R. G. Josse $\cdot$ L. A. Leiter
}

Received: 8 August 2010 /Accepted: 3 September 2010 /Published online: 27 October 2010

(C) The Author(s) 2010. This article is published with open access at Springerlink.com

\begin{abstract}
Aims/hypothesis Sugar has been suggested to promote obesity, diabetes and coronary heart disease (CHD), yet fruit, despite containing sugars, may also have a low glycaemic index (GI) and all fruits are generally recommended for good health. We therefore assessed the effect of fruit with special emphasis on low GI fruit intake in type 2 diabetes.

Methods This secondary analysis involved 152 type 2 diabetic participants treated with glucose-lowering agents who completed either 6 months of high fibre or low GI dietary advice, including fruit advice, in a parallel design. Results Change in low GI fruit intake ranged from -3.1 to 2.7 servings/day. The increase in low GI fruit intake significantly
\end{abstract}

Electronic supplementary material The online version of this article (doi:10.1007/s00125-010-1927-1) contains supplementary material, which is available to authorised users.

D. J. A. Jenkins $(\bowtie) \cdot$ K. Srichaikul $\cdot$ C. W. C. Kendall $•$

J. L. Sievenpiper - S. Abdulnour - A. Mirrahimi - S. Nishi •

X. He $\cdot$ S. Lee $\cdot$ Y. T. So $\cdot$ A. Esfahani $\cdot$ S. Mitchell $\cdot$ T. L. Parker $\cdot$

E. Vidgen $\cdot$ R. G. Josse $\cdot$ L. A. Leiter

Clinical Nutrition \& Risk Factor Modification Center,

St Michael's Hospital,

Toronto, ON, Canada M5C 2T2

e-mail: NutritionProject@smh.ca

D. J. A. Jenkins $\cdot$ R. G. Josse $\cdot$ L. A. Leiter

Division of Endocrinology and Metabolism, St Michael's Hospital,

Toronto, ON, Canada

D. J. A. Jenkins $\cdot$ K. Srichaikul $\cdot$ C. W. C. Kendall •

J. L. Sievenpiper $\cdot$ A. Mirrahimi $\cdot \mathrm{S}$. Nishi $\cdot$ X. He $\cdot$ S. Lee $\cdot$

Y. T. So $\cdot$ A. Esfahani $\cdot$ E. Vidgen $\cdot$ R. G. Josse $\cdot$ L. A. Leiter

Department of Nutritional Sciences, Faculty of Medicine,

University of Toronto,

Toronto, ON, Canada predicted reductions in $\mathrm{HbA}_{1 \mathrm{c}}(r=-0.206, p=0.011)$, systolic blood pressure $(r=-0.183, p=0.024)$ and CHD risk $(r=-0.213, p=0.008)$. Change in total fruit intake ranged from -3.7 to 3.2 servings/day and was not related to study outcomes. In a regression analysis including the eight major carbohydrate foods or classes of foods emphasised in the low GI diet, only low GI fruit and bread contributed independently and significantly to predicting change in $\mathrm{HbA}_{1 \mathrm{c}}$. Furthermore, comparing the highest with the lowest quartile of low GI fruit intake, the percentage change in $\mathrm{HbA}_{1 \mathrm{c}}$ was reduced by $-0.5 \% \mathrm{HbA}_{1 \mathrm{c}}$ units $\left(95 \%\right.$ CI $0.2-0.8 \mathrm{HbA}_{1 \mathrm{c}}$ units, $p<0.001)$.

Conclusions/interpretation Low GI fruit consumption as part of a low GI diet was associated with lower $\mathrm{HbA}_{1 \mathrm{c}}$,
S. Abdulnour

Institute of Medical Science, Faculty of Medicine,

University of Toronto,

Toronto, ON, Canada

C. Meneses

Hospital Santo Espírito de Angra do Heroísmo,

Azores, Portugal

D. J. A. Jenkins • R. G. Josse - L. A. Leiter

Department of Medicine, Faculty of Medicine,

University of Toronto,

Toronto, ON, Canada

\section{J. L. Sievenpiper}

Department of Pathology and Molecular Medicine,

Faculty of Health Sciences,

McMaster University,

Hamilton, ON, Canada 
blood pressure and CHD risk and supports a role for low GI fruit consumption in the management of type 2 diabetes. Trial registration ClinicalTrials.gov NCT00438698 Funding The Canadian Institutes of Health Research; Canada Research Chair Endowment of the Federal Government of Canada, Loblaw Companies, and Barilla (Italy).

Keywords CHD risk - Dietary guidelines - Dietary sugars . Fructose $\cdot$ Fruit $\cdot \mathrm{GI} \cdot \mathrm{HbA}_{1 \mathrm{c}} \cdot \mathrm{HDL}$-cholesterol $\cdot$ Low glycaemic index . Type 2 diabetes

$\begin{array}{ll}\text { Abbreviations } \\ \text { CHD } & \text { Coronary heart disease } \\ \text { GI } & \text { Glycaemic index } \\ \text { TG } & \text { Triacylglycerol }\end{array}$

\section{Introduction}

Increased sugar intake and, more recently, high fructose consumption, especially from high fructose corn syrup, has attracted attention for its potential negative impact on health. Concerns have been raised especially in respect to body weight control and increased risk of diabetes and coronary heart disease (CHD) [1-7]. On the other hand, sugars in fruit are viewed in a very different light and the public are recommended to eat more fruit, together with vegetables and wholegrain cereals, as part of general dietary advice in order to maintain health and avoid specific diseases such as diabetes, cardiovascular disease and cancer [8-12].

This apparent contradiction in relation to the effect of sugars may be due in part to the fibre and cell wall structure of fruit, which limits the rate of sugar absorption in the gastrointestinal tract resulting in flatter glycaemic responses [13].Thus, a flatter glycaemic response has been seen after consumption of whole fruit when compared with fruit puree and even more so when compared with drinking fruit juice [13, 14].

Fruit in general have a glycaemic index (GI) that ranges from 56 to 103 GI units (on the bread scale). We hypothesised that selection of those at the lower end of the range may provide the greatest benefit in reducing the overall glycaemic response. As a result we emphasised the use of low GI fruit in a previously published study examining the role of a low GI diet in type 2 diabetes. This study has now provided us with the opportunity to assess the relation of low GI fruit intake with the metabolic changes observed as part of the overall low GI diet [15].

\section{Methods}

Participants Details of the study protocol have been reported previously [15]. Recruitment took place from
May 2004 to December 2006, with the last follow-up visit at the end of May 2007. Of those recruited, 210 were found to be eligible and were randomised. Eligible participants were men or postmenopausal women with type 2 diabetes who were taking oral agents to control their diabetes, with medications stable for the previous 3 months and who had $\mathrm{HbA}_{1 \mathrm{c}}$ values at screening between $6.5 \%$ and $8.0 \%$ (Table 1). None had clinically significant cardiovascular, renal or liver disease (alanine transaminase $>$ three times the upper limit of normal) and none was undergoing treatment for cancer. Individuals were accepted after surgery or myocardial infarction providing an event-free 6 month period had elapsed prior to the study. This study is a secondary analysis, but differs from the original study [15] in that it focuses on the 152 participants who completed the study and also provided 7 day food records, which were used to determine fruit intake.

The study was approved by the research ethics board of St Michael's Hospital and the University of Toronto, and written consent was obtained from all participants.

Protocol In this secondary analysis of completer data from a previously published study [15], participants were randomised to one of two parallel 6 month treatments: a low GI diet or a high cereal fibre diet. During the study, equally strong emphasis was placed by dietitians on the potential value of both treatments.

Participants were seen at the Clinical Nutrition and Risk Factor Modification Center of St Michael's Hospital, a University of Toronto Teaching Hospital, at baseline, weeks 2 and 4, and thereafter at monthly intervals until the end of the 6 month period. During the first month, participants received instructions on the diet to which they were allocated. At all centre visits, participants were weighed in indoor clothing without shoes and a fasting blood sample was taken. Blood pressure was measured seated on three occasions at 1 min intervals using an Omron automatic sphygmomanometer (OMRON Healthcare, Burlington, ON, Canada) and the mean of the three measurements was taken. In addition, participants brought with them their 7 day food records covering the week prior to the visit and these were discussed with the dietitians.

During the study, participants were asked to maintain their exercise pattern and keep their glucose-lowering agents constant throughout the study.

Dietary interventions General dietary advice conformed to the National Cholesterol Education Program Adult Treatment Panel III (NCEP ATP III) and the ADA guidelines [16] to reduce saturated fat and cholesterol intakes [17]. Of all the participants, $84.9 \%$ were overweight (BMI $\geq 25 \mathrm{~kg} / \mathrm{m}^{2}$ ) and $50.7 \%$ were obese (BMI $\geq 30 \mathrm{~kg} / \mathrm{m}^{2}$ ) and wished to lose weight. They were informed that this was not a weight loss 
Table 1 Baseline characteristics of study participants
Values are mean \pm SD unless stated otherwise

Differences in categorical variables were assessed by binomial tests of equality

Differences in continuous variables were assessed by two-sample $t$ test

\begin{tabular}{|c|c|c|c|}
\hline Characteristic & $\begin{array}{l}\text { High cereal fibre } \\
(n=73)\end{array}$ & $\begin{array}{l}\text { Low GI } \\
(n=79)\end{array}$ & $\begin{array}{l}\text { Significance of difference } \\
p \text { value }\end{array}$ \\
\hline Age (years) & $62 \pm 9$ & $61 \pm 10$ & 0.669 \\
\hline Sex (male/female, $n / n)$ & $45 / 28$ & $51 / 28$ & $0.305 / 0.553$ \\
\hline Weight $(\mathrm{kg})$ & $86 \pm 16$ & $87 \pm 21$ & 0.885 \\
\hline BMI $\left(\mathrm{kg} / \mathrm{m}^{2}\right)$ & $31 \pm 5$ & $30 \pm 6$ & 0.732 \\
\hline \multicolumn{4}{|l|}{ Ethnicity, $n(\%)$} \\
\hline European & $46(63)$ & $57(72)$ & 0.162 \\
\hline Indian & $14(19)$ & $11(14)$ & 0.345 \\
\hline Far Eastern & $3(4)$ & $6(8)$ & 0.254 \\
\hline African & $8(11)$ & $3(4)$ & 0.113 \\
\hline Hispanic & $1(1)$ & $2(3)$ & 0.500 \\
\hline Native American & $1(1)$ & $0(0)$ & 0.500 \\
\hline Smokers, $n(\%)$ & $2(3)$ & $8(10)$ & 0.055 \\
\hline Glucose (mmol/l) & $7.56 \pm 1.52$ & $7.64 \pm 1.75$ & 0.767 \\
\hline $\mathrm{HbA}_{1 \mathrm{c}}(\%)$ & $7.03 \pm 0.46$ & $7.17 \pm 0.57$ & 0.100 \\
\hline No. participants $<7$ & 36 & 29 & 0.229 \\
\hline No. participants $\geq 7$ & 37 & 50 & 0.099 \\
\hline Total cholesterol (mmol/l) & $4.24 \pm 0.75$ & $4.18 \pm 0.95$ & 0.661 \\
\hline LDL-cholesterol (mmol/l) & $2.48 \pm 0.64$ & $2.47 \pm 0.89$ & 0.934 \\
\hline HDL-cholesterol (mmol/l) & $1.14 \pm 0.28$ & $1.06 \pm 0.31$ & 0.103 \\
\hline TG (mmol/l) & $1.36 \pm 0.71$ & $1.42 \pm 0.79$ & 0.643 \\
\hline Systolic blood pressure (mmHg) & $128 \pm 14$ & $127 \pm 16$ & 0.727 \\
\hline Diastolic blood pressure (mmHg) & $74 \pm 9$ & $73 \pm 10$ & 0.846 \\
\hline Duration of diabetes (years) & $7 \pm 6$ & $9 \pm 7$ & 0.062 \\
\hline Hypoglycaemic agents, $n(\%)$ & $73(100)$ & 77 (97) & 0.403 \\
\hline Thiazolidinedione & $25(34)$ & $25(32)$ & 0.556 \\
\hline Biguanide & $58(79)$ & $63(80)$ & 0.358 \\
\hline Sulfonylurea & $29(40)$ & $49(62)$ & 0.015 \\
\hline Meglitinides (non-sulfonylurea) & $2(3)$ & $1(1)$ & 0.500 \\
\hline Alpha glucosidase inhibitors & $2(3)$ & $3(4)$ & 0.500 \\
\hline Cholesterol-lowering medications, $n(\%)$ & $46(63)$ & $55(70)$ & 0.539 \\
\hline Blood pressure medications, $n(\%)$ & $52(71)$ & $52(66)$ & 0.213 \\
\hline
\end{tabular}

study but appropriate advice was given on portion size and fat intake to help them meet their body weight objectives. Participants were also provided with a checklist with either low GI or high cereal fibre food options as approximately $15 \mathrm{~g}$ carbohydrate servings. The number of carbohydrate servings prescribed covered $42-43 \%$ of total dietary energy. Three servings of fruit and five servings of vegetables were encouraged on both treatments. On the low GI treatment, the carbohydrate intakes emphasised were low GI breads, breakfast cereals, parboiled rice, pasta, beans, barley, bulgar and low GI fruit. Temperate climate fruit, which are generally low GI, were the focus and included apples, pears, citrus fruit (oranges, tangerines and grapefruit), berries (strawberries, raspberries, cranberries, blackberries and blueberries) and the Prunus family (nectarines, peaches and plums). On the cereal fibre treatment, the focus was on wholewheat breads, breakfast cereals and tropical fruit with glycaemic indices that were closer to that of the average diet, such as bananas, mangoes, guavas, grapes, raisins, watermelon and cantaloupe. Low GI or temperate climate fruit had GI values of $<70$ GI units (bread scale), with the exception of blueberries, with a value of 76 GI units, based on recent values for individuals without diabetes [18]. Higher GI fruit, predominantly tropical fruit, had values $>70$ GI units [18]. Participants were also advised against eating fruit recommended on the alternative treatment. Checklists were completed by participants on a daily basis throughout the study and 7 day diet records were completed prior to each visit. Adherence was assessed from the 7 day diet records. The overall aim was to achieve a $10-20 \%$ reduction in GI on the low GI diet while keeping dietary fibre similar between treatments. 
Biochemical analyses Blood glucose was measured in the hospital routine analytical laboratory by a glucose oxidase method using a Random Access Analyzer and reagents (SYNCHRON LX Systems, Beckman Coulter, Brea, CA, USA) (CV 1.9\%). $\mathrm{HbA}_{1 \mathrm{c}}$ was analysed by a designated HPLC method (Tosoh G7 Automated HPLC Analyzer, Grove City, OH, USA) (CV 1.7\%). Serum was analysed for total cholesterol, triacylglycerol (TG) and HDL-cholesterol, also using a Random Access Analyzer (CV 1.5-2.4\%). Diets were assessed for available carbohydrate (total carbohydrate-fibre) using a computer program based on US Department of Agriculture data [19].

Statistical analyses The primary outcome was $\mathrm{HbA}_{1 \mathrm{c}}$, with glucose, total cholesterol, LDL-cholesterol, HDL-cholesterol, TG, blood pressure, body weight and CHD risk as secondary measures. Analyses were undertaken on individuals who completed the study and also provided diet records at the start of and during the study $(n=152)$.

Baseline data are expressed as means \pm SDs. All other data are expressed as means $(95 \% \mathrm{CI})$. All analyses were carried out using SAS software, version 9.2 [20].

Pearson correlations as well as partial correlations controlling for body weight change and change in fibre intake were undertaken to determine the relation of low GI fruit to measures of glycaemic control and CHD risk. The data from the two treatments were pooled and both the absolute differences in servings of fruit, and the carbohydrate from fruit expressed as a percentage of the total carbohydrate, were related to the percentage changes from baseline in the outcome measures. Overall 10 year CHD risk was calculated according to the Framingham cardiovascular risk equation [21]. In our current analyses, only raw and frozen fruit were included. We excluded processed fruit products such as juices, canned fruit and jams as unmodified fruit was the focus of our assessment. Two-sample Student's $t$ test was used to assess differences between treatments at baseline and between changes across treatments. Binomial tests of equality were used to assess differences at baseline for categorical variables.

Participants were also divided into four equal groups based on the magnitude of the change they made in low GI fruit intake, expressed as a percentage of daily available carbohydrate from fruit [(available carbohydrate from fruit $\div$ total available carbohydrate in the diet $) \times 100]$. The significance of differences between those in the upper quartile of change in low GI fruit intake vs those in the lowest quartile was assessed using an ANOVA model (Proc GLM in SAS version 9.2) [20], with percentage change in measurements as the response variable.

Finally, to assess the contribution of low GI fruit to the absolute change in $\mathrm{HbA}_{1 \mathrm{c}}$, as the primary outcome in the context of the other major low GI food components, a regression analysis was undertaken in SAS using an ANOVA model. In this analysis, the assessment of each dietary component was carried out in a model adjusted for change in fibre $(\mathrm{g} / \mathrm{kJ}$ or $\mathrm{kcal})$ and total fruit intake $(\%$ of available carbohydrate). The eight individual low GI dietary components were fruit, bread, breakfast cereals, pasta, beans, parboiled rice, barley and bulgar, each expressed as a percentage of total carbohydrate.

\section{Results}

Of the 210 individuals randomised, 155 completed the study [15] and dietary records for both pretreatment and end of treatment were available for 152 participants. At baseline, individuals taking either high cereal fibre or low GI diets were similar in terms of physical characteristics, ethnicity, smoking status, glycaemic and lipid control and medication use, with the exception of higher sulfonylurea use by the low GI diet group (Table 1).

Fruit consumption At baseline, participants were consuming 1.4 servings ( $95 \%$ CI $1.2-1.6$ ) of raw and frozen fruit daily. The most commonly consumed fruits were bananas followed, in descending order, by apples, oranges, pears, tangerines and berries (Fig. 1). Low GI fruit accounted for 0.7 servings/day (95\% CI $0.5-0.9$ ) and 0.7 servings/day (95\% CI 0.5-0.9) came from higher GI fruit.

At the end of 6 months, participants following the low GI diet increased their low GI fruit consumption from 0.7 (95\% CI $0.6-0.9)$ to 1.3 (95\% CI $1.1-1.5)$ servings/day $(p<0.001)$. On the high cereal fibre diet low GI fruit consumption was reduced from $0.8(95 \%$ CI $0.6-0.9)$ to 0.3 (95\% CI 0.2-0.4) servings/day $(p<0.001)$. Total fruit intake remained similar on both the low GI and high fibre diets (2.0 servings/day for both).

On the low GI diet, the change in total fruit and low GI fruit ranged from -3.5 to 3.0 servings/day and -1.9 to 2.7 servings/day, respectively. On the high fibre diet, the respective figures were total fruit -3.7 to 3.2 servings/day and low GI fruit -3.1 to 0.5 servings/day. As this is a secondary analysis, pooling the data from both treatments was undertaken. The changes in total fruit and low GI fruit intake ranged from -3.7 to 3.2 servings per day and -3.1 to 2.7 servings per day, respectively, a substantial span of approximately six servings of low GI fruit per day.

Relation of changes in total and low GI fruit intake to changes in measures of glycaemic control and CHD risk factors No significant associations were seen between total fruit intake and changes in measures of glycaemic control and CHD risk factors. 
Fig. 1 The distribution of average daily carbohydrate (g/day) from consumption of individual fruit for all participants at baseline $(n=152)$. Black bars, low GI fruit; white bars, higher GI fruit

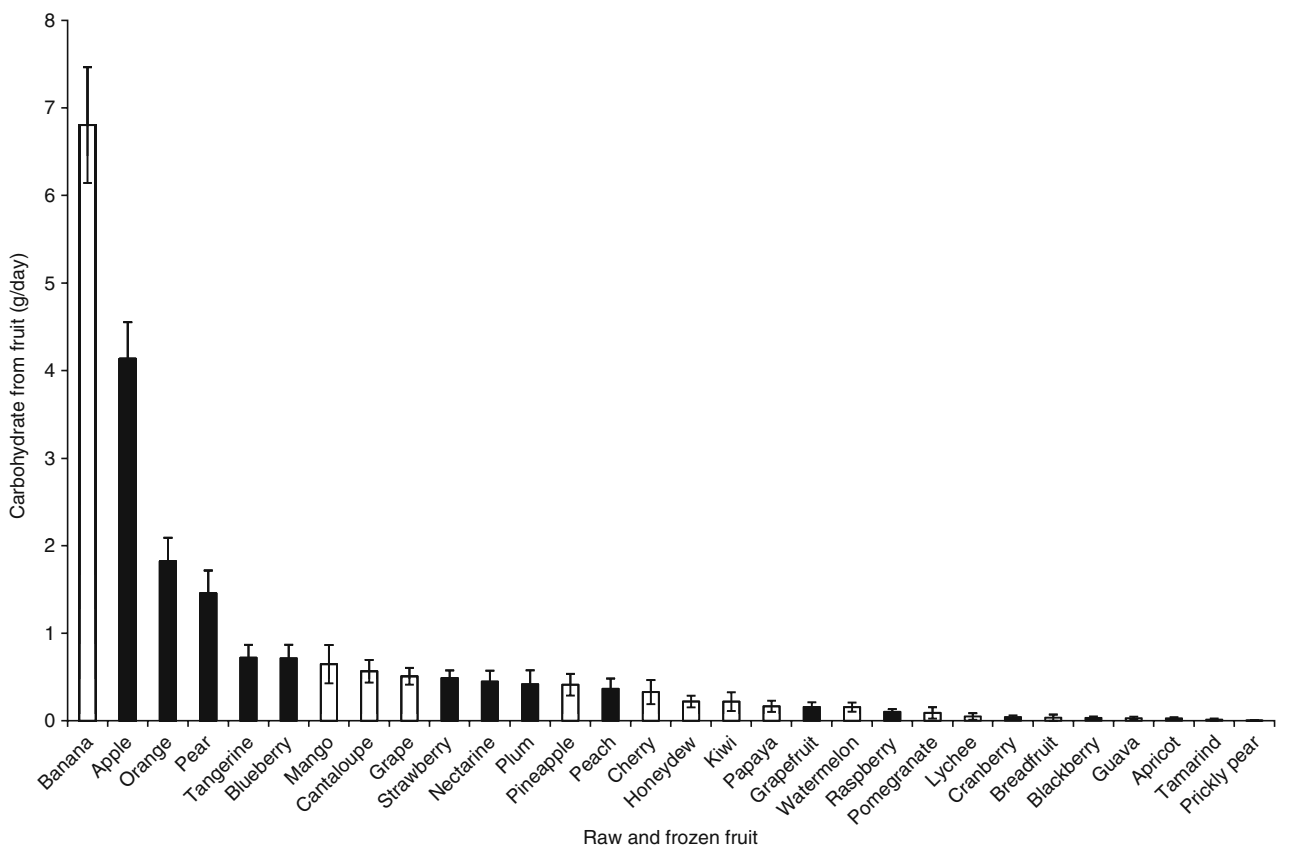

Low GI fruit intake, expressed as servings, was related to a reduction in $\mathrm{HbA}_{1 \mathrm{c}}(\%)(r=-0.206, p=0.011)$, systolic blood pressure $(r=-0.183, p=0.024)$ and CHD risk $(r=-0.213$, $p=0.008)$. Expressed as a percentage of total carbohydrate intake there was again a negative relation with $\mathrm{HbA}_{1 \mathrm{c}}$ $(r=-0.218, p=0.007)$ and calculated CHD risk $(r=-0.192$, $p=0.018$ ), but a positive relation with HDL-cholesterol $(r=0.216, p=0.008$, Table 2).

Controlling for the effect of change in body weight in a partial correlation analysis did not alter the associations between the change in low GI fruit as percentage of total carbohydrate consumed and the reduction in $\mathrm{HbA}_{1 \mathrm{c}}$ $(r=-0.269, r=0.001)$. This assessment suggested that the effect of low GI fruit on $\mathrm{HbA}_{1 \mathrm{c}}$ was largely independent of weight loss.

Relation of changes in individual fruit intake to changes in measures of glycaemic control and CHD risk factors Individually, citrus fruit and berry consumption as a percentage of total carbohydrate intake was related to a reduction in the primary outcome, $\mathrm{HbA}_{1 \mathrm{c}}$ (Table 2). Apple consumption correlated negatively with TG, the total cholesterol/HDLcholesterol ratio and CHD risk, and positively with HDLcholesterol. Berry intake was related negatively to glucose and blood pressure but positively to TG. No significant associations were seen with pear and prunus fruit consumption.

Glycaemic control and body weight in the highest and lowest quartiles Participants were divided into quartiles according to the magnitude of their change in low GI fruit intake across the 6 month treatment period (Electronic supplementary material [ESM] Tables 1-3). There was a relative difference of 2.2 servings/day (95\% CI 1.9-2.4, $p<0.001$ ) between the changes in low GI fruit intake for the highest and lowest quartile (ESM Table 3), and an absolute difference of 1.6 servings/day (95\% CI $1.2-1.9, p<0.001$ ) at the end of the study.

The highest quartile of low GI fruit showed a significantly greater reduction from baseline in $\mathrm{HbA}_{1 \mathrm{c}}(7.2 \%$ to $6.5 \%$ or a mean reduction of $-0.8 \% \mathrm{HbA}_{1 \mathrm{c}}$ units, $95 \% \mathrm{CI}-1,-0.5$, $p<0.001)$ compared with the lowest quartile $(7.0 \%$ to $6.7 \%$ or a mean reduction of $-0.3 \% \mathrm{HbA}_{1 \mathrm{c}}$ units, $95 \% \mathrm{CI}-0.5$, $-0.1, p=0.01)$. These two changes were significantly different from each other, with a mean difference of $0.5 \%$ $\mathrm{HbA}_{1 \mathrm{c}}$ units, 95\% CI $0.2-0.8, p<0.001$ (equivalent to a $-6 \%$ percentage reduction in $\mathrm{HbA}_{1 c}$; Fig. 2).

No significant differences were seen in the changes in body weight or BMI. Even after adjusting the quartiles of low GI fruit intake according to change in BMI, the significance of the treatment difference previously observed in $\mathrm{HbA}_{1 \mathrm{c}}$ remained unaltered. Also, the increase in fibre intake was greatest in the fourth quartile of low GI fruit intake. Furthermore, after adjustment for the change in fibre intake, the increase in low GI fruit was still associated with an improvement in $\mathrm{HbA}_{1 \mathrm{c}}(r=-0.21, p=0.009)$.

Serum lipids, blood pressure and CHD risk in highest vs lowest quartiles HDL-cholesterol was significantly increased by $7.3 \%(95 \%$ CI $1.2-13.3 \%, p=0.019$; ESM Table 3) on the highest quartile of low GI fruit (a change of $0.05 \mathrm{mmol} / \mathrm{l}, 95 \%$ CI $0.03-0.08, p=0.045$ ) compared with 
Table 2 Association of low GI fruit intake with study measurements in 152 completers

\begin{tabular}{|c|c|c|c|c|c|c|c|}
\hline \multirow{2}{*}{$\begin{array}{l}\text { Study outcomes } \% \Delta \\
\text { week } 24-0\end{array}$} & \multirow[t]{2}{*}{ Value } & \multicolumn{6}{|c|}{ Change in fruit intake ( $\%$ of total available carbohydrate intake) } \\
\hline & & Apples & $\begin{array}{l}\text { Citrus (oranges, } \\
\text { tangerines, grapefruits }\end{array}$ & $\begin{array}{l}\text { Berries (strawberries, } \\
\text { raspberries, blueberries, } \\
\text { blackberries, cranberries) }\end{array}$ & Pears & $\begin{array}{l}\text { Prunus family (plum, } \\
\text { peaches, nectarines) }\end{array}$ & $\begin{array}{l}\text { Total low } \\
\text { GI fruit }\end{array}$ \\
\hline \multirow[t]{2}{*}{$\mathrm{HbA}_{1 \mathrm{c}}$} & $r$ & -0.135 & -0.219 & -0.228 & 0.121 & -0.073 & -0.218 \\
\hline & $p$ & 0.096 & 0.007 & 0.005 & 0.136 & 0.372 & 0.007 \\
\hline \multirow[t]{2}{*}{ Glucose } & $r$ & -0.125 & -0.008 & -0.167 & -0.014 & -0.030 & -0.141 \\
\hline & $p$ & 0.124 & 0.918 & 0.040 & 0.863 & 0.715 & 0.083 \\
\hline \multirow[t]{2}{*}{ Weight } & $r$ & -0.016 & 0.112 & -0.096 & 0.123 & -0.136 & -0.014 \\
\hline & $p$ & 0.846 & 0.170 & 0.239 & 0.132 & 0.095 & 0.865 \\
\hline \multirow[t]{2}{*}{ Total cholesterol } & $r$ & -0.098 & -0.001 & 0.019 & -0.052 & 0.103 & -0.020 \\
\hline & $p$ & 0.228 & 0.990 & 0.813 & 0.522 & 0.208 & 0.804 \\
\hline \multirow[t]{2}{*}{ LDL-cholesterol } & $r$ & 0.013 & -0.007 & -0.070 & -0.009 & 0.059 & 0.007 \\
\hline & $p$ & 0.872 & 0.928 & 0.395 & 0.911 & 0.473 & 0.930 \\
\hline \multirow[t]{2}{*}{ HDL-cholesterol } & $r$ & 0.223 & 0.156 & -0.105 & 0.098 & 0.060 & 0.216 \\
\hline & $p$ & 0.006 & 0.055 & 0.199 & 0.231 & 0.459 & 0.008 \\
\hline \multirow[t]{2}{*}{ TG } & $r$ & -0.210 & -0.069 & 0.233 & -0.090 & 0.103 & -0.070 \\
\hline & $p$ & 0.009 & 0.396 & 0.004 & 0.268 & 0.208 & 0.394 \\
\hline \multirow[t]{2}{*}{ C-reactive protein } & $r$ & 0.031 & -0.004 & -0.071 & 0.151 & 0.050 & 0.065 \\
\hline & $p$ & 0.716 & 0.960 & 0.403 & 0.075 & 0.559 & 0.443 \\
\hline \multirow[t]{2}{*}{ Systolic blood pressure } & $r$ & -0.017 & -0.006 & -0.302 & -0.035 & -0.034 & -0.122 \\
\hline & $p$ & 0.839 & 0.940 & 0.000 & 0.666 & 0.682 & 0.134 \\
\hline \multirow[t]{2}{*}{ Diastolic blood pressure } & $r$ & -0.017 & -0.140 & -0.162 & 0.035 & 0.069 & -0.067 \\
\hline & $p$ & 0.833 & 0.086 & 0.046 & 0.667 & 0.400 & 0.410 \\
\hline \multirow[t]{2}{*}{$\mathrm{CHD}$ risk } & $r$ & -0.211 & -0.089 & -0.067 & -0.099 & 0.039 & -0.192 \\
\hline & $p$ & 0.009 & 0.274 & 0.409 & 0.223 & 0.635 & 0.018 \\
\hline
\end{tabular}

the lowest quartile (a change of $-0.03 \mathrm{mmol} / \mathrm{l}, 95 \% \mathrm{CI}$ $-0.15,0.11, p=0.217)$. Similarly, the relative reduction in systolic blood pressure between quartiles was $-4 \%(95 \% \mathrm{CI}$ $-8,0 \%, p=0.044$; ESM Table 3 ), as was the calculated 10 year CHD risk $(-13 \%, 95 \% \mathrm{CI}-23,-3 \%, p=0.010)$.

Contribution of low GI fruit to the overall low GI intervention Assessment of the contribution of the components of the low GI diet to the change in $\mathrm{HbA}_{1 \mathrm{c}}$ was carried out using a regression model, controlling for change in fibre and total fruit intake. Only low GI fruit and low GI bread intake were significant predictors $(r=-0.233, p=0.0017$ and $r=-0.228, p=0.002$, respectively; Table 3 ). When both low GI fruit and low GI bread were assessed in the same regression model, both independently predicted the change in $\mathrm{HbA}_{1 \mathrm{c}}(p=0.031$ and $p=0.038$, respectively).

\section{Discussion}

In this secondary analysis of a low GI study, consumption of two additional daily servings of low GI fruit (the difference between the lowest and highest quartiles of intake) was associated with a significant benefit in glycaemic control, blood lipids and blood pressure. The effect of altering the nature of the fruit eaten has not previously been assessed in diabetes to our knowledge, but may have benefits for both micro- and macrovascular disease, the treatment of which is the major therapeutic goal for type 2 diabetes.

Despite dietary advice to the general public to eat more fruit and vegetables and encouraging data from cohort studies indicating less cardiovascular and cerebrovascular disease [12, 22-25], the results of the few randomised controlled trials of the impact on cardiovascular disease and cancer have been disappointing [26-29]. However, fruit advice has been general and has not focused on low GI fruit [26-29].

On the other hand, very small increases in fructose intake of 7-10 g (a 'catalytic' amount) have been shown to prime glucose metabolism, reducing postprandial glucose concentrations [30-33] and increasing liver glycogen synthesis threefold by increasing flux through glycogen synthase, assessed by magnetic resonance spectroscopy [34]. At the 


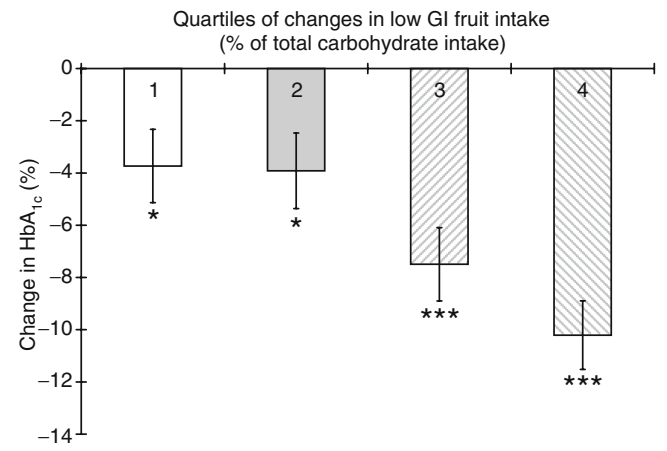

Fig. 2 Changes in $\mathrm{HbA}_{1 \mathrm{c}}(\%)$ for four quartiles of change in low GI fruit intake. The difference between extremes of quartiles (quartile 1 vs quartile 4$)$ was significant $(p=0.001)$. Within-treatment differences were assessed by paired $t$ test $\left({ }^{*} p \leq 0.05\right.$ and $\left.* * * p \leq 0.001\right)$. Different coloured bars with quartile numbers at the top of the bars represent different quartiles of change in low GI fruit intake

same time, it has also been demonstrated that low-dose fructose infusion restores the inhibitory effect of hyperglycaemia in reducing net hepatic glucose output in type 2 diabetes, possibly by increasing fructose-1-phosphate. In turn, fructose-1-phosphate displaces glucokinase from its nuclear regulatory protein and allows its translocation to the cell surface to facilitate portal glucose uptake and its retention within hepatocytes [35]. It may be, therefore, that the increase in low GI fruit, by releasing an additional $6 \mathrm{~g}$ or more of fructose from the small intestine into the circulation over an extended period of time, has a disproportionately large effect in reducing postprandial blood glucose excursions.

The situation is very different for large amounts of fructose $(17-25 \%$ of dietary energy intake) incorporated into sweetened beverages, baked goods and breakfast cereals [6, 36-40]. Early on, high fructose intakes were associated with increased TG levels [36]. Later studies noted increases in LDL-cholesterol [6, 37, 38]. Most

Table 3 Regression analysis of total fruit, fibre and key low GI diet components against change in $\mathrm{HbA}_{1 \mathrm{c}}$

\begin{tabular}{lccc}
\hline $\begin{array}{l}\text { Key diet } \\
\text { components }^{\mathrm{a}}\end{array}$ & Adjusted $r$ & $\begin{array}{l}\text { Regression model, } \\
p \text { value }\end{array}$ & $\begin{array}{l}\text { Key component, } \\
p \text { value }\end{array}$ \\
\hline Low GI fruit & -0.233 & 0.011 & 0.0017 \\
Low GI bread & -0.228 & 0.012 & 0.002 \\
Parboiled rice & -0.069 & 0.299 & 0.124 \\
Legumes & -0.047 & 0.346 & 0.157 \\
Low GI cereal & -0.032 & 0.372 & 0.176 \\
Pasta & -0.050 & 0.456 & 0.252 \\
Bulgar & -0.052 & 0.462 & 0.258 \\
Barley & -0.101 & 0.689 & 0.672 \\
\hline
\end{tabular}

\footnotetext{
${ }^{\mathrm{a}}$ All models were adjusted for change in fibre $(\mathrm{g} / \mathrm{kJ}$ or kcal) and total fruit (\% of available carbohydrate) intake
}

recently, raised postprandial TG responses have been reported after high fructose consumption, especially in men, together with increased remnant particle concentrations, more visceral fat and impaired carbohydrate tolerance [6]. These effects of high fructose intake over time would be expected to increase the risk of diabetes and cardiovascular disease. At more modest intake levels, sucrose and fructose intake have not been associated with increased CHD risk [41-43].

Fruits in general are also sources of fibre, minerals, antioxidants and phenolics, which may reduce serum lipids and oxidative damage, lower blood pressure, improve diabetes control and, over time, decrease CHD outcomes. However, definitive roles for all these components remain to be established [44-48]. Furthermore their relevance to the present study is less clear as it was the nature (GI) rather than the quantity of fruit eaten that was altered. On the other hand, cohort studies have assessed the effect of dietary GI on diabetes incidence and CHD [41-43, 49, 50] and significant positive associations have been found in the larger studies [41, 49, 50]. Nevertheless, the nature of the individual fruit consumed was not reported in these studies [41-43, 49, 50].

A weakness of the present study may be seen as singling out low GI fruit for detailed assessment when low GI fruit consumption was only one of the strategies used to reduce the overall GI of the diet. Nevertheless, in regression analysis involving all eight components of the low GI diet, low GI fruit intake was one of only two independent determinants of change in $\mathrm{HbA}_{1 \mathrm{c}}$. This association remained even after adjustment for fibre and total fruit intake. In addition, weight loss was also present on both the low GI and high fibre treatments. However, correction for body weight change in a partial regression analysis did not alter the significance of associations previously seen with simple Pearson correlations between low GI fruit intake and $\mathrm{HbA}_{1 \mathrm{c}}$ and calculated CHD risk. Finally, although fruits are of special interest for a number of reasons, including their role as a natural source of fructose in the diet, there has been great difficulty in increasing fruit intake, despite universal advice to the public.

The strengths of the study included the first attempt to define the health benefits of individual fruit in type 2 diabetes, the detailed dietary recording — which has allowed the type of fruit consumed in the diet to be clearly identified and the amounts determined - and the substantial participant numbers, which enabled statistical significance to be established.

In conclusion, the data suggest that selection of low GI fruit is associated with improvement in $\mathrm{HbA}_{1 \mathrm{c}}$. Such changes may also favourably affect HDL-cholesterol, blood pressure and overall CHD risk. Further studies are required to confirm these findings and determine optimal levels of fruit consumption to maximise glycaemic control. 
Acknowledgements The authors wish to thank S. Casey and P. Yse (Loblaw Companies) for their support of GI research and the study participants for their attention to detail and enthusiasm. No compensation was given. The study was funded by the Canadian Institutes of Health Research, Canada Research Chair Endowment of the Federal Government of Canada, Loblaw Companies, and Barilla (Italy). None of the funding organisations or sponsors played any role in: the design and conduct of the study; the collection, management, analysis and interpretation of the data; or the preparation, review or approval of the manuscript. J. L. Sievenpiper has received travel funding from the Coca-Cola Company; travel funding and honoraria from Archer Daniels Midland and the International Life Sciences Institute (ILSI) North America; and research support, consultant fees and travel funding from Pulse Canada.

Duality of interest D. J. A. Jenkins has served on the Scientific Advisory Board of Unilever, the Sanitarium Company and the California Strawberry Commission. D. J. A. Jenkins and C. W. C. Kendall have been on the speakers' panel for the Almond Board of California. C. W. C. Kendall, E. Vidgen, T. L. Parker, S. Mitchell, K. Srichaikul, S. Abdulnour and S. Nishi receive partial salary funding from research grants provided by Unilever, Loblaws and the Almond Board of California. D. J. A. Jenkins has received honoraria for scientific advice from the Almond Board of California, Barilla and Unilever Canada. His wife is a director of GI Laboratories, Toronto, ON, Canada.

Open Access This article is distributed under the terms of the Creative Commons Attribution Noncommercial License which permits any noncommercial use, distribution, and reproduction in any medium, provided the original author(s) and source are credited.

\section{References}

1. Schulze MB, Manson JE, Ludwig DS et al (2004) Sugarsweetened beverages, weight gain, and incidence of type 2 diabetes in young and middle-aged women. JAMA 292:927-934

2. Bray GA, Nielsen SJ, Popkin BM (2004) Consumption of highfructose corn syrup in beverages may play a role in the epidemic of obesity. Am J Clin Nutr 79:537-543

3. Le KA, Ith M, Kreis R et al (2009) Fructose overconsumption causes dyslipidemia and ectopic lipid deposition in healthy subjects with and without a family history of type 2 diabetes. Am J Clin Nutr 89:1760-1765

4. Bantle JP (2009) Dietary fructose and metabolic syndrome and diabetes. J Nutr 139:1263S-1268S

5. Montonen J, Jarvinen R, Knekt P, Heliovaara M, Reunanen A (2007) Consumption of sweetened beverages and intakes of fructose and glucose predict type 2 diabetes occurrence. J Nutr 137:1447-1454

6. Stanhope KL, Schwarz JM, Keim NL et al (2009) Consuming fructose-sweetened, not glucose-sweetened, beverages increases visceral adiposity and lipids and decreases insulin sensitivity in overweight/obese humans. J Clin Invest 119:1322-1334

7. Wu T, Giovannucci E, Pischon T et al (2004) Fructose, glycemic load, and quantity and quality of carbohydrate in relation to plasma C-peptide concentrations in US women. Am J Clin Nutr 80:1043-1049

8. US Department of Health and Human Services (2005) US Department of Agriculture. Dietary guidelines for American 2005. US Government Printing Office, Washington, DC

9. Bantle JP, Wylie-Rosett J, Albright AL et al (2008) Nutrition recommendations and interventions for diabetes: a position statement of the American Diabetes Association. Diab Care 31 (Suppl 1):S61-S78
10. Lichtenstein AH, Appel LJ, Brands $M$ et al (2006) Diet and lifestyle recommendations revision 2006: a scientific statement from the American Heart Association Nutrition Committee. Circulation 114:82-96

11. Kushi LH, Byers T, Doyle C et al (2006) American Cancer Society guidelines on nutrition and physical activity for cancer prevention: reducing the risk of cancer with healthy food choices and physical activity. Cancer J Clin 56:254-281

12. Liu S, Manson JE, Lee IM et al (2000) Fruit and vegetable intake and risk of cardiovascular disease: the Women's Health Study. Am J Clin Nutr 72:922-928

13. Haber GB, Heaton KW, Murphy D, Burroughs LF (1977) Depletion and disruption of dietary fibre. Effects on satiety, plasma-glucose, and serum-insulin. Lancet 2:679-682

14. Bolton RP, Heaton KW, Burroughs LF (1981) The role of dietary fiber in satiety, glucose, and insulin: studies with fruit and fruit juice. Am J Clin Nutr 34:211-217

15. Jenkins DJ, Kendall CW, McKeown-Eyssen G et al (2008) Effect of a low-glycemic index or a high-cereal fiber diet on type 2 diabetes: a randomized trial. JAMA 300:2742-2753

16. Franz MJ, Bantle JP, Beebe CA et al (2004) Nutrition principles and recommendations in diabetes. Diab Care 27(Suppl 1):S36S46

17. NCEP (2001) Executive Summary of the Third Report of the National Cholesterol Education Program (NCEP) Expert Panel on Detection, Evaluation, And Treatment of High Blood Cholesterol In Adults (Adult Treatment Panel III). JAMA 285:2486-2497

18. Atkinson FS, Foster-Powell K, Brand-Miller JC (2008) International tables of glycemic index and glycemic load values: 2008 . Diab Care 31:2281-2283

19. The Agricultural Research Service (1992) Composition of foods, agriculture handbook no 8. US Department of Agriculture, Washington

20. Institute SAS (2006) SAS/STAT user's guide. SAS Institute, Cary

21. Wilson PW, Castelli WP, Kannel WB (1987) Coronary risk prediction in adults (the Framingham Heart Study). Am J Cardiol 59:91G-94G

22. Fung TT, Stampfer MJ, Manson JE, Rexrode KM, Willett WC, Hu FB (2004) Prospective study of major dietary patterns and stroke risk in women. Stroke 35:2014-2019

23. Joshipura KJ, Hu FB, Manson JE et al (2001) The effect of fruit and vegetable intake on risk for coronary heart disease. Ann Intern Med 134:1106-1114

24. Heidemann C, Schulze MB, Franco OH, van Dam RM, Mantzoros CS, Hu FB (2008) Dietary patterns and risk of mortality from cardiovascular disease, cancer, and all causes in a prospective cohort of women. Circulation 118:230-237

25. He FJ, Nowson CA, MacGregor GA (2006) Fruit and vegetable consumption and stroke: meta-analysis of cohort studies. Lancet 367:320-326

26. Pierce JP, Natarajan L, Caan BJ et al (2007) Influence of a diet very high in vegetables, fruit, and fiber and low in fat on prognosis following treatment for breast cancer: the Women's Healthy Eating and Living (WHEL) Randomized Trial. JAMA 298:289-298

27. Beresford SA, Johnson KC, Ritenbaugh C et al (2006) Low-fat dietary pattern and risk of colorectal cancer: the Women's Health Initiative Randomized Controlled Dietary Modification Trial. JAMA 295:643-654

28. Schatzkin A, Lanza E, Corle D et al (2000) Lack of effect of a low-fat, high-fiber diet on the recurrence of colorectal adenomas. Polyp Prevention Trial Study Group. N Engl J Med 342:1149-1155

29. Howard BV, Van Horn L, Hsia J et al (2006) Low-fat dietary pattern and risk of cardiovascular disease: the Women's Health Initiative Randomized Controlled Dietary Modification Trial. JAMA 295:655-666 
30. Moore MC, Cherrington AD, Mann SL, Davis SN (2000) Acute fructose administration decreases the glycemic response to an oral glucose tolerance test in normal adults. J Clin Endocrinol Metab $85: 4515-4519$

31. Moore MC, Davis SN, Mann SL, Cherrington AD (2001) Acute fructose administration improves oral glucose tolerance in adults with type 2 diabetes. Diab Care 24:1882-1887

32. Heacock PM, Hertzler SR, Wolf BW (2002) Fructose prefeeding reduces the glycemic response to a high-glycemic index, starchy food in humans. J Nutr 132:2601-2604

33. Vaisman N, Niv E, Izkhakov Y (2006) Catalytic amounts of fructose may improve glucose tolerance in subjects with uncontrolled non-insulin-dependent diabetes. Clin Nutr 25:617-621

34. Peterson KF, Laurent D, Yu C, Cline GW, Shulman GI (2001) Stimulating effects of low-dose fructose on insulin-stimulated hepatic glycogen synthesis in humans. Diabetes 50:1263-1268

35. Hawkins M, Gabriely H, Wozniak R, Vilcu C, Shamoon H, Rossetti L (2002) Fructose improves the ability of hyperglycemia per se to regulate glucose production in type 2 diabetes. Diabetes 51:606-614

36. Crapo PA, Kolterman OG, Henry RR (1986) Metabolic consequence of two-week fructose feeding in diabetic subjects. Diab Care 9:111-119

37. Bantle JP, Swanson JE, Thomas W, Laine DC (1992) Metabolic effects of dietary fructose in diabetic subjects. Diab Care 15:1468-1476

38. Swanson JE, Laine DC, Thomas W, Bantle JP (1992) Metabolic effects of dietary fructose in healthy subjects. Am J Clin Nutr $55: 851-856$

39. Bantle JP, Raatz SK, Thomas W, Georgopoulos A (2000) Effects of dietary fructose on plasma lipids in healthy subjects. Am J Clin Nutr 72:1128-1134

40. Stanhope KL, Griffen SC, Bair BR, Swarbrick MM, Keim NL, Havel PJ (2008) Twenty-four-hour endocrine and metabolic profiles following consumption of high-fructose corn syrup-, sucrose-, fructose-, and glucose-sweetened beverages with meals. Am J Clin Nutr 87:1194-1203

41. Liu S, Willett WC, Stampfer MJ et al (2000) A prospective study of dietary glycemic load, carbohydrate intake, and risk of coronary heart disease in US women. Am J Clin Nutr 71:1455-1461

42. Meyer KA, Kushi LH, Jacobs DR Jr, Slavin J, Sellers TA, Folsom AR (2000) Carbohydrates, dietary fiber, and incident type 2 diabetes in older women. Am J Clin Nutr 71:921-930

43. van Dam RM, Visscher AW, Feskens EJ, Verhoef P, Kromhout D (2000) Dietary glycemic index in relation to metabolic risk factors and incidence of coronary heart disease: the Zutphen Elderly Study. Eur J Clin Nutr 54:726-731

44. Sesso HD, Buring JE, Christen WG et al (2008) Vitamins E and C in the prevention of cardiovascular disease in men: the Physicians' Health Study II randomized controlled trial. JAMA 300:2123-2133

45. Huxley RR, Neil HA (2003) The relation between dietary flavonol intake and coronary heart disease mortality: a meta-analysis of prospective cohort studies. Eur J Clin Nutr 57:904-908

46. Rimm EB, Katan MB, Ascherio A, Stampfer MJ, Willett WC (1996) Relation between intake of flavonoids and risk for coronary heart disease in male health professionals. Ann Intern Med 125:384-389

47. Hertog MG, Sweetnam PM, Fehily AM, Elwood PC, Kromhout D (1997) Antioxidant flavonols and ischemic heart disease in a Welsh population of men: the Caerphilly Study. Am J Clin Nutr 65:1489-1494

48. Hertog MG, Feskens EJ, Hollman PC, Katan MB, Kromhout D (1993) Dietary antioxidant flavonoids and risk of coronary heart disease: the Zutphen Elderly Study. Lancet 342:1007-1011

49. Salmeron J, Ascherio A, Rimm EB et al (1997) Dietary fiber, glycemic load, and risk of NIDDM in men. Diab Care 20: $545-550$

50. Salmeron J, Manson JE, Stampfer MJ, Colditz GA, Wing AL, Willett WC (1997) Dietary fiber, glycemic load, and risk of non-insulin-dependent diabetes mellitus in women. JAMA 277: $472-477$ 